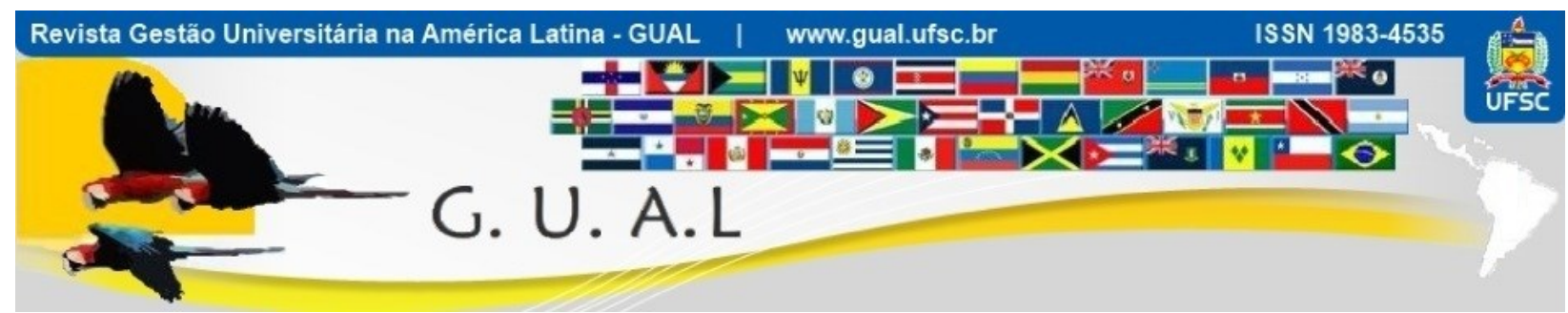

DOI: http://dx.doi.org/10.5007/1983-4535.2013v6n4p280

\title{
DISTRIBUIÇÃO REGIONAL DAS INSTITUIÇÕES DE ENSINO SUPERIOR GRATUITO NO ESTADO DE SANTA CATARINA: A LACUNA NA MESORREGIÃO DO VALE DO ITAJAII E AS CONTRADIÇÕES DAS POLÍTICAS PÚBLICAS DE EXPANSÃO DE VAGAS
}

\begin{abstract}
REGIONAL DISTRIBUTION OF FREE HIGHER EDUCATION INSTITUTIONS IN THE SANTA CATARINA STATE: A GAP IN THE MESOREGION OF ITAJAÍ VALLEY AND THE CONTRADICTIONS OF PUBLIC POLITICS OF EXPANSION OF VACANCIES
\end{abstract}

Clóvis Reis, Doutor clovis@,furb.br Fundação Universidade Regional de Blumenau - FURB

Jamile Delagnelo Fagundes da Silva, Doutorando jamiledelagnelo@yahoo.com.br Fundação Universidade Regional de Blumenau - FURB

Rubens Staloch, Mestrando rubensstaloch@yahoo.com.br Fundação Universidade Regional de Blumenau - FURB

Recebido em 29/novembro/2013

Aprovado em 29/novembro/2013

Sistema de Avaliação: Double Blind Review

(c) (†) $\ominus$ Esta obra está sob uma Licença Creative Commons Atribuição-Uso. 


\title{
RESUMO
}

O debate sobre democratização do Ensino Superior no Brasil é um tema recorrente, sendo que a garantia do acesso é uma das questões centrais destas discussões. Tratar da "democratização do ensino superior" implica no enfrentamento de questões ligadas ao acesso de um maior número de estudantes a esse grau de ensino. O presente artigo tem como objeto central analisar as políticas públicas de acesso com base no mapeamento das Instituições de Ensino Superior públicas gratuitas no Estado de Santa Catarina, considerando para o mapeamento a divisão geopolítica mesorregional do IBGE. Trata-se de uma pesquisa de cunho qualitativo interpretativo. O corpus da pesquisa foi constituído por dados do IBGE e informações disponibilizadas pelas instituições. Após a análise dos dados, se pode dizer que 37,5\% das IES públicas gratuitas que oferta mais de três cursos superiores estão concentradas na mesorregião da Grande Florianópolis, em detrimento de outras regiões do território catarinense. Verifica-se que apenas 3,39\% dos municípios do Estado possuem IES pública gratuita que oferta mais de três cursos superiores.

Palavras-chave: Políticas Públicas. IES pública gratuita. Santa Catarina. Mapeamento.

\begin{abstract}
The debate about democratization of higher education in Brazil is a recurring theme, and ensuring access is a central issue in these discussions. Treat the "democratization of higher education" means in tackling issues relating to access a greater number of students to this education level. This article has as main object to analyze the public politics of access based on the mapping of Free Public Institutions of Higher Education in the Santa Catarina State, considering for the mapping the IBGE's mesorregional geopolitical division. This is a survey of interpretive qualitative approach. The research corpus consisted of IBGE's data and information provided by the institutions. After the data analyzed, we can say that $37.5 \%$ of free public higher education institutions that offers more than three upper courses are concentrated in the Florianópolis's region, in detriment of others Santa Catarina's regions. It is found that only $3.39 \%$ of municipalities in the state have free public Institutions of Higher Education (HEIs) that offers more the three courses.
\end{abstract}

Keywords: Public Politic. Free Public HEIs. Santa Catarina. Mapping. 


\section{INTRODUÇÃO}

As questões relacionadas ao acesso nas Instituições de Ensino Superior - IES, estão diretamente ligadas à localização destas IES no território. Nesta perspectiva, o que se busca neste artigo é mapear como está atualmente, no ano de 2013, esta localização das IES públicas gratuitas no Estado de Santa Catarina, levando em consideração as IES de competência Federal, Estadual e Municipal. O recorte foi direcionado às instituições públicas gratuitas, uma vez que o direito à educação encontra-se genericamente previsto na redação do art. $6^{\circ}$. da CF/88, no Capítulo II - Dos Direitos Sociais, que diz: "São direitos sociais a educação, a saúde, o trabalho, a moradia, o lazer, a segurança, a previdência social, a proteção à maternidade e à infância, a assistência aos desamparados, na forma dessa Constituição" (CONSTITUIÇÃO DA REPÚBLICA FEDERATIVA DO BRASIL, 2008, p. 24) Porém, a efetivação do direito à educação depende não só da sua previsão normativa subjetiva, mas de instrumentos jurídicos que obriguem especialmente o Estado a promovê-la. Para conformar tal situação, faz-se necessário analisar especificamente os dispositivos presentes nos arts. 205 ao 214 da $\mathrm{CF} / 88$. O art. 205 definiu genericamente o direito à educação: “A educação, direito de todos e dever do Estado e da família, será promovida e incentivada com a colaboração da sociedade, visando ao pleno desenvolvimento da pessoa, seu preparo para o exercício da cidadania e sua qualificação para o trabalho" (CONSTITUIÇÃO DA REPÚBLICA FEDERATIVA DO BRASIL, 2008, p. 106).

Sendo assim, o Estado deverá não somente fornecer a educação gratuitamente nos estabelecimentos oficiais, como estabelecer políticas públicas visando à ampliação desse sistema, como por exemplo, através da implantação de novas IES públicas gratuitas. Antes de seguir adiante, cabe salientar de que neste trabalho, política pública é entendida como “diretrizes, princípios norteadores de ação do poder público: regras de relações entre poder público e sociedade, mediações entre autores da sociedade e do estado" (TEIXEIRA, 2002, p. 2).

De acordo com Secchi, política pública pode ser encarada como a soma de atividades do governo, que age diretamente ou através de delegação, e que influencia a vida dos cidadãos. Assim, uma política pública é uma diretriz elaborada para enfrentar um problema público (SECCHI, 2011). No caso deste artigo, a demanda refere-se à educação superior, mais 
especificamente, a política pública à implantação de IES no estado de Santa Catarina, avaliada de acordo com a distribuição das IES públicas gratuitas no território.

Como característica central, a política pública então pode ser expressa como sendo um ciclo conceitual, descrita por Heidemann e Salm:

O ciclo conceitual das políticas públicas compreende pelo menos quatro etapas: a primeira refere-se às decisões políticas tomadas para resolver problemas sociais previamente estudados. Depois de formuladas, as políticas decididas precisam ser implementadas, pois sem ações elas não passam de boas intenções. Numa terceira etapa, procura-se verificar se as partes interessadas numa política foram satisfeitas em suas demandas. E, enfim, as políticas devem ser avaliadas, com vistas a sua continuidade, aperfeiçoamento, reformulação, ou, simplesmente, descontinuidade (HEIDEMANN e SALM, 2004, p. 34).

A atuação do Estado através de políticas públicas na educação superior pública e gratuita é necessária para a formação de quadros qualificados, garantindo assim, o desenvolvimento do território nacional, regional e local. De acordo com Costa, et al. (2011) após um estudo sobre o financiamento público e expansão da educação superior federal no Brasil a partir das políticas do Programa de Apoio a Planos de Reestruturação e Expansão das Universidades Federais (REUNI), instituído pelo Decreto ${ }^{\circ}$ 6.096, de 24 de abril de 2007.

O REUNI tem como principal objetivo ampliar o acesso e a permanência dos alunos na educação superior. (REUNI, 2013). Em 2011 foi apresentado o REUNI 2, elencando que “é preciso que o Ministério da Educação opere com mais energia sobre todas as instituições federais do país. Este desafio deve ser enfrentado sem deixar de lado a qualidade da educação oferecida nestas instituições" (COSTA, et al., 2011, p. 125). Ainda, de acordo com os autores, é preciso que o governo Federal prossiga com a criação e o desenvolvimento das universidades federais, instalando-as nas regiões que existam demandas de cursos, aumentando a possibilidade de acesso ao ensino superior, o que é relevante à democratização da educação superior brasileira.

Como objetivo, durante a apresentação do REUNI 2, em 2011, foram elencados pelo Ministério da Educação os critérios para definir o número de campus universitário e de escolas de educação profissional por estado, sendo três as dimensões levadas em consideração: Social, Geográfico e Desenvolvimento. Na dimensão Social é levada em consideração a universalização de atendimento aos Territórios da Cidadania $^{1}$, aos municípios populosos e com baixa receita per capita e os municípios que apresentam índices de extrema 
pobreza. Na dimensão Geográfica são levados em consideração o atendimento prioritário aos municípios com mais de 50000 habitantes ou microrregiões não atendidas, universalização do atendimento às mesorregiões brasileira, municípios não atendidos por escolas federais, interiorização da oferta pública de educação profissional e ensino superior e oferta de educação superior federal por estado abaixo da média nacional. E, por último, na dimensão do Desenvolvimento, são levados em consideração municípios com Arranjos Produtivos Locais - APLs identificados e entorno de grandes investimentos (MINISTÉRIO DA EDUCAÇÃO, 2011).

No âmbito Estadual, de acordo com o Plano 20 da Universidade do Estado de Santa Catarina (UDESC), a expansão da universidade é um desafio de estar em sintonia com a sociedade catarinense. Para cumprir sua função social, a UDESC necessita assumir uma postura de crescimento por intermédio da ampliação nas áreas de ensino nos diferentes níveis, pesquisa e extensão e na diversificação da oferta de seus serviços prestados à sociedade, assim, a gestão da UDESC enfatiza "ser fundamental importância o seu desenvolvimento pleno, a fim de corresponder com as expectativas da comunidade catarinense, cumprindo seu papel enquanto instituição pública e gratuita do Estado de Santa Catarina” (Universidade do Estado de Santa Catarina, 2010, p. 49).

A expansão da UDESC deverá ser balizada, combinando a missão, a visão de futuro e as políticas norteadoras estabelecidas no Plano 20. Para o seu processo de a instituição adota as seguintes políticas, sugeridas pela Comissão de Sistematização e aprovadas no Conselho Universitário (CONSUNI) em 31/05/2007, Resolução $n^{\circ}$ 39/2007: a) Indução do desenvolvimento; b) Compatibilização de empregabilidade, sustentabilidade e relevância social; c) Desenvolvimento de parcerias internas, visando a não duplicação; d) Oferta baseada em futura verticalização; e) Vocacionamento da infraestrutura e equipamentos; f) Otimização da infraestrutura física; g) Utilização acadêmica e administrativa da Tecnologia da Informação e Comunicação (TIC); h) Interação com a sociedade; e i) Busca da mobilização do poder constituído e dos diversos segmentos da sociedade.

Para tanto, no que tange à expansão externa da UDESC, ou seja, por meio da implantação de novos centros no Estado, definiram-se os seguintes critérios: a) a posição geográfica de cada região com relação às outras unidades da UDESC [...]; b as condições de infraestrutura física e de serviços; c) a quantidade de cursos superiores já existentes na região; d) a quantidade de alunos matriculados no segundo grau; e) o índice de desenvolvimento 
humano; e) sustentabilidade econômico-social. (UNIVERSIDADE DO ESTADO DE SANTA CATARINA, 2010).

Assim, de acordo com o Plano 20 da UDESC, está sendo pensada a expansão externa através de novos centros para as regiões: Meio-Oeste, Extremo Sul e Extremo Oeste. Para verificar se no Estado de Santa Catarina estão sendo levados em consideração os critérios para a expansão das IES, que visem o acesso ao ensino superior público gratuito faz-se uma análise de como estão distribuídas as IES públicas gratuitas no estado através de um mapeamento ancorado na divisão geopolítica mesorregional do IBGE que estão pautados nos conceitos de espaço, território e região, explicitados na próxima seção.

\section{DOS CONCEITOS BÁSICOS: ESPAÇO, TERRITÓRIO E REGIÃO}

Para que se possa entender a configuração regional catarinense e, também, analisar a distribuição regional das instituições de ensino públicas e gratuitas, é preciso, antes de tudo, entender alguns conceitos básicos tais como: espaço, território e região.

Para Lefebvre (1992 [1974]) “o espaço é um produto social” (p.26). Este espaço compreende as relações sociais e não pode ser resumido ao espaço físico, ele é o espaço da vida social, onde ocorrem as relações (sociais) entre os seres. Sua base é a natureza ou espaço físico, o qual o homem transforma com seu trabalho. Lefebvre afirma que a natureza não produz, ela cria, e, somente o homem é capaz de produzir através do trabalho. O autor ainda considera que o modo de produção vigente em cada sociedade é determinante para a produção do espaço. Cada modo de produção tem como resultado uma produção espacial diferente, de forma que o espaço é produzido pelo processo de produção e, ao mesmo tempo, dá suporte ao seu desenvolvimento. O espaço social agrupa as coisas produzidas e envolve suas interrelações, permitindo ações de produção e consumo. O espaço social inclui objetos naturais e sociais, os quais são também relações.

Os objetos possuem formas, mas "o trabalho social os transforma, reorganizando suas posições dentro das configurações espaços-temporais sem afetar necessariamente suas materialidades, seus estados naturais" (LEFEBVRE, 1992, p.76), ou seja, altera sua função sem alterar sua forma. Assim, “Tempo e espaço são inseparáveis [...], espaço implica em tempo e vice versa" (p.118). Em Espacio y Política (1976) Lefebvre afirma que:

Do espaço não se pode dizer que seja um produto como qualquer outro, um objeto ou uma soma de objetos, uma coisa ou uma coleção de coisas, uma 
mercadoria ou um conjunto de mercadorias. Não se pode dizer que seja simplesmente um instrumento, o mais importante de todos os instrumentos, $\mathrm{o}$ pressuposto de toda produção e de todo o intercâmbio. Estaria essencialmente vinculado com a produção das relações (sociais) de produção. (LEFEBVRE, 1976, p.34).

De acordo com Lefebvre (1992 [1974]), então, o espaço não é algo dado, ele é produzido pelo homem a partir da transformação da natureza pelo seu trabalho. As relações sociais são constituintes do espaço e é a partir delas que o homem altera a natureza. As relações sociais de produção, consumo e reprodução (social) são determinantes na produção do espaço. O espaço deve ser estudado a partir das formas, funções e estruturas, e novas relações podem dar funções diferentes para formas preexistentes, pois o espaço não desaparece, ele abarca elementos de diferentes tempos.

A partir dos estudos de Lefebvre sobre o conceito de espaço, os geógrafos passam a utilizar do conceito de espaço geográfico (objeto de estudo da Geografia) que permitisse a inserção e consolidação da Geografia como ciência social. Para Milton Santos (2002 [1996]), o espaço geográfico é formado por um conjunto indissociável, solidário e também contraditório, de sistemas de objetos e sistemas de ações, não considerados isoladamente, mas como o quadro único (p.63). Para o autor, a natureza é a origem, ela quem fornece as coisas, as quais são transformadas em objetos pela ação do homem através da técnica. "No princípio, tudo eram coisas, enquanto hoje tudo tende a ser objeto, já que as próprias coisas, dádivas da natureza, quando utilizadas pelos homens a partir de um conjunto de intenções sociais, passam, também, a ser objetos." (SANTOS, 2002, p.65).

Para o autor, a técnica é "a principal forma de relação entre o homem e a natureza" e é definida como "um conjunto de meios instrumentais e sociais, com os quais o homem realiza sua vida, produz e, ao mesmo tempo, cria espaço" (p.29). Assim, a partir destes conceitos, podemos dizer que o território catarinense e suas devidas divisões são ancorados em um conjunto de meios instrumentais e intenções sociais. A técnica é um conjunto de "instrumentos" que a sociedade utiliza para alterar a natureza e criar o espaço geográfico; é a técnica que une os sistemas de ações e os sistemas de objetos, permitindo a relação homemnatureza e homem-homem e, desta forma, a produção do espaço geográfico. Porém, as técnicas são propagadas de forma desigual e implantadas de forma seletiva no espaço.

Para Hartshorne, o espaço é o espaço absoluto, um conjunto de pontos que tem existência em si, independente de qualquer coisa, aparece como um receptáculo que apenas 
contém as coisas, "é como se cada porção do espaço absoluto fosse o lócus de uma combinação única em relação a qual não se poderia conceber generalizações" (CORREIA, 1995, p. 19). Assim, Correia diz que "o espaço organizado pelo homem desempenha um papel na sociedade, condicionando-a, compartilhando do complexo processo de existência e reprodução social" (CORREIA, 1995, p.28).

Faz-se necessário ainda, estudar as demais categorias analíticas do espaço geográfico descritas por Milton Santos: “a paisagem, a configuração territorial, a divisão territorial do trabalho, o espaço produzido ou produtivo, as rugosidades e as formas-conteúdo.” Há também a necessidade de estudar os recortes espaciais a partir de temas como o "da região e do lugar, o das redes e das escalas" (SANTOS, 2002, p.22).

Diversos autores como Claude Raffestin, Roger Brunet, Rogério Haesbaert e Milton Santos se dedicam a estudar o conceito de território, sendo, consensual que o mesmo é indissociável da noção de poder e que não pode ser encarado unicamente como os limites político-administrativos dos países. O território deve ser estudado tomando como referência o espaço, pois ele é formado a partir do espaço geográfico, daí a indissociabilidade entre os dois. Cada autor apresenta uma visão particular de território, sendo ela influenciada pela realidade estudada, por seus objetivos e por sua concepção de espaço.

O território, no presente trabalho, é entendido como resultado da impressão do poder no espaço, territorializado pelo sujeito territorial (seres humanos), que é movido pela intencionalidade. Já, o conceito de região, em meados do século XIX, estava fortemente ligado à região natural, pois a influência da região natural é decisiva na configuração de uma sociedade. Assim, o conceito de região natural nasce desta "ideia de que o ambiente tem um certo domínio sobre a orientação do desenvolvimento da sociedade" (COSTA GOMES, 1995, p. 55).

Contrário a essa perspectiva do meio natural explicar as diferenças sociais e espaciais, Lefebvre defende a ideia do possibilismo: o meio ambiente propõe, o homem dispõe. Nasce assim, novos conceitos de região geográfica ou região paisagem que tem no homem a ação transformadora sobre um determinado ambiente. "A região é uma realidade concreta, física, ela existe como um quadro de referência para a população que aí vive" (COSTA GOMES, 1995, p.57).

As regiões são, em primeiro caso, o resultado de uma divisão do espaço que é em princípio submetido essencialmente sempre às mesmas variáveis, 
definindo-se, pois através desta divisão um sistema espacial classificatório, uniforme e hierárquico. No segundo caso, as regiões são concebidas como produtos relativos, fruto da aplicação de critérios particulares que operam internamente na explicabilidade daqueles que as propõem (COSTA GOMES, 1995, p. 70).

Ainda neste contexto, Santos (1999) procura definir, caracterizar e identificar os tipos de eventos que ocorrem na sociedade. $\mathrm{O}$ autor faz isto a partir de suas considerações e de outros autores que abordam a temática, enfatiza a temporalidade do evento e sua espacialidade, também a duração e sobreposição dos mesmos. Inicia deixando clara a existência de diferentes acepções e sentidos utilizados para o vocábulo evento. "O evento também pode ser o vetor das possibilidades existentes numa formação social, isto é, num país, ou numa região, ou num lugar, considerados esse país, essa região, esse lugar como um conjunto circunscrito e mais limitado que o mundo" (SANTOS, 1999, p.115).

Neste contexto, destaca-se a importância do evento como vetor de possibilidades existentes numa formação social, sendo útil ao processo de conquista e organização do espaço socialmente habitado. Também é necessário destacar o termo lugar, que seria afinal o lócus do evento, onde efetivamente este irá ocorrer (SANTOS, 1999). O autor ainda ressalta que, não há evento sem ator, sem sujeito. Surge aí a ideia de inovação: "Uma inovação é um caso especial de evento, caracterizada pelo aporte a um dado ponto, no tempo e no espaço, de um dado que nele renova um modo de fazer, de organizar ou de entender a realidade" (SANTOS, 1999, p. 117-118).

Deste modo,

Os eventos são atuais, absolutos, individualizados, finitos, sucessivos. Mas na medida em que se estendem uns sobre os outros, participando uns dos outros, eles estão criando a continuidade do mundo vivente em movimento (Leslie Paul, 1961, p.126), ou, em outras palavras, a continuidade temporal e a coerência espacial. É assim que as situações geográficas se criam e recriam (SANTOS, 1999, p.124).

Assim, o evento modifica o território, conjuntamente com a ação humana (condição necessária ao evento), produzindo novos lugares e consequentemente, reconfigurando o espaço. É pautado nesta perspectiva, na compreensão destes conceitos, se pode dizer que os recortes regionais atuais ainda são múltiplos e complexos acrescidos da proposição política, de controle e gestão de um território. A região, por sua vez, serve como elemento chave de um sistema explicativo, de contextos políticos, institucionais, econômicos e culturais. Seguindo este padrão está o território catarinense acerca da distribuição das IES públicas 
gratuitas. Assim, se faz necessária, antes do mapeamento das IES, a caracterização políticoeconômica do estado catarinense, e também, a sua devida divisão mesorregional.

\section{DADOS POLÍTICOS-ECONÔMICOS DO TERRITÓRIO CATARINENSE}

Santa Catarina é um dos menores estados do país com 95 284, $436 \mathrm{Km}^{2}$. Está localizada na região sul do Brasil, ocupando 1,12\% do território nacional, possuindo cerca de $5,26 \%$ do número total de municípios do país. A evolução da divisão político-administrativa municipal catarinense relaciona-se com os períodos políticos e econômicos nacionais (RANGEL, 2005), refletindo a formação sócio-espacial (SANTOS, 1979) do Brasil meridional, da gênese dos primeiros povoados no século XVII até as emancipações municipais da atualidade.

A capital catarinense é Florianópolis (segunda cidade com maior número populacional), sendo o estado composto por 295 municípios, possuindo inúmeras atrações turísticas, cultura diversificada e características regionais muito fortes. Em termos de características gerais, de acordo com o Instituto Brasileiro de Geografia e Estatística (IBGE), Santa Catarina possui:

Tabela 01 Dados Gerais de Santa Catarina, 2013

\begin{tabular}{ll}
\hline População* (mil hab) & 6.248 .436 \\
Área $\left(\mathrm{km}^{2}\right)$ & $95.736,165$ \\
Densidade demográfica* $\left(\mathrm{hab} / \mathrm{km}^{2}\right)$ & 65,29 \\
Número de Municípios** & 295 \\
IDH$^{3} * *$ & 0,8742 \\
PIB (bilhões) & $\mathrm{R} \$ 129,8$ \\
PIB per capita (mil) & $\mathrm{R} \$ 21.215,00$
\end{tabular}

Fonte: IBGE/PENUD/FECAM, 2013.

*Censo Demográfico de 2010.

**De acordo com o Censo 2010, o estado de Santa Catarina possuía 293 municípios, porém, não contabilizava os municípios de Balneário Rincão emancipado pela lei 12.668 e Pescaria Brava emancipado pela lei 12.690/03, totalizando em 2013 o número de 295 municípios - FECAM, 2013. ***Dados do PNUD, 2011.

Com relação às 5 (cinco) cidades catarinenses com maior número populacional, se pode destacar: 


\begin{tabular}{|l|c|c|}
\hline & Município & Total de Habitantes (mil) \\
\hline $\mathbf{1}$ & Joinville & 515.288 \\
\hline $\mathbf{2}$ & Florianópolis & 421.240 \\
\hline $\mathbf{3}$ & Blumenau & 309.011 \\
\hline $\mathbf{4}$ & São José & 209.804 \\
\hline $\mathbf{5}$ & Criciúma & 192.308 \\
\hline
\end{tabular}

Quadro 01 Municípios com maior número populacional, SC. Fonte: IBGE, Censo Demográfico 2010.

Para o presente trabalho será utilizada a divisão geopolítica territorial regional com base nos dados do Instituto Brasileiro de Geografia e Estatística - IBGE, que divide o território catarinense em 6 (seis) mesorregiões e 20 (vinte) microrregiões.

As 6 (seis) mesorregiões são divididas em Oeste Catarinense, Norte Catarinense, Serrana, Vale Do Itajaí, Sul Catarinense e Grande Florianópolis:

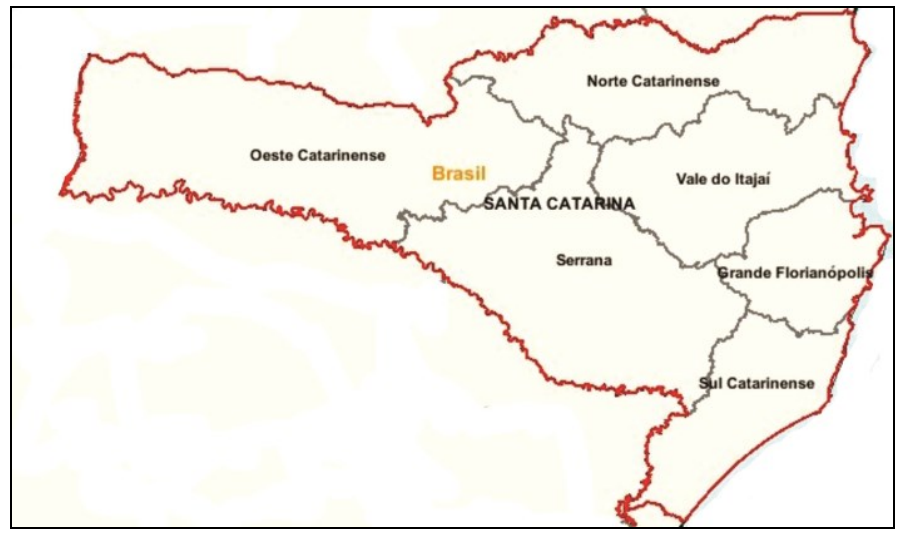

Figura 1 Mesorregiões do Estado de Santa Catarina. Fonte: SIDRA-IBGE.

Já as 20 microrregiões estão divididas da seguinte forma: São Miguel do Oeste, Chapecó, Xanxerê, Concórdia, Joaçaba, Curitibanos, Canoinhas, Rio do Sul, Campos de Lages, Ituporanga, São Bento do Sul, Joinville, Blumenau, Itajaí, Tijucas, Tabuleiro, Florianópolis, Tubarão, Criciúma e Araranguá, representadas graficamente: 


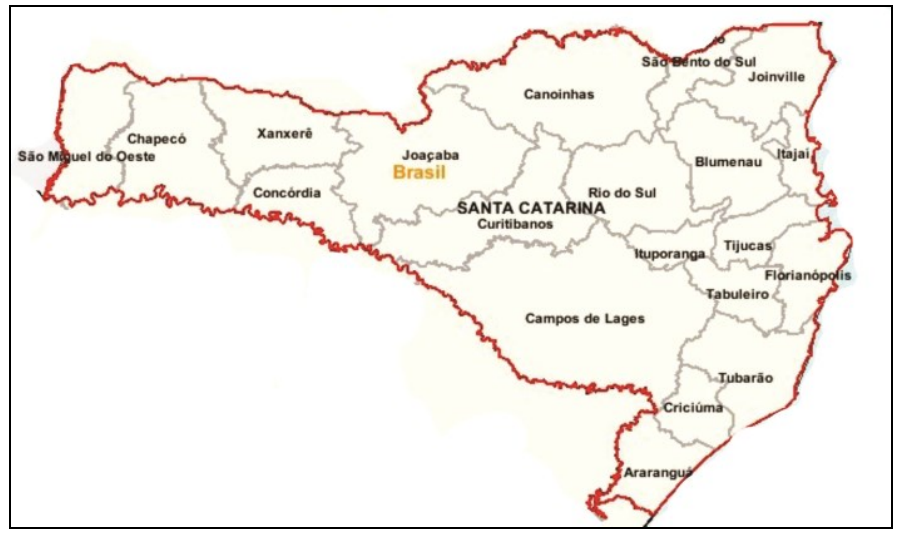

Figura 2 Microrregiões do Estado de Santa Catarina. Fonte: SIDRA-IBGE.

Com relação aos aspectos econômicos, foi no Litoral, que de início com a economia de subsistência, que se iniciaram as primeiras atividades econômicas, administrativas e sociais de Santa Catarina. Hoje, o estado possui uma grande expressão industrial, está entre os estados que mais empregam no ramo da indústria de transformação. Em sua frente estão somente os estados de São Paulo, Minas Gerais e Rio Grande do Sul. Para Goularti Filho uma das características que marca a economia de Santa Catarina é a especialização regional, sendo que cada microrregião é especializada num determinado segmento da indústria, com uma forte inserção nacional e internacional, e, em muitos casos, líder na produção nacional (GOULARTI FILHO, 2002). O processo de industrialização catarinense se deu de forma descentralizada, sem uma urbanização excessiva.

O setor industrial de Santa Catarina concentra-se na maior parte em indústrias de pequeno e médio porte, contando com a presença de algumas empresas multinacionais. Estas empresas, principalmente as do nordeste do estado se destacam não somente por serem pioneiras em alguns ramos, mas principalmente pelo alto nível de qualidade dos seus produtos, sendo reconhecidos não apenas pelo restante do país, mas também por outros países, o que reflete no nível de exportação.

No desenvolvimento industrial catarinense, destacam-se desde o século XIX, os imigrantes alemães, italianos e seus descendentes. Desde o início de 1960, o desenvolvimento dessa região já era muito diversificado, destacavam-se as indústrias têxteis, de móveis, madeireiras, e de produtos metalúrgicos. Com o passar do tempo, as empresas madeireiras vieram perdendo força devido à destruição das florestas e as novas leis ambientais mais rigorosas e com maior fiscalização, no entanto os produtos metalúrgicos, os motores e os materiais de transporte ganharam impulso e acabaram se desenvolvendo. 
As cidades de Joinville e Blumenau além da grande concentração industrial vêm apresentando um crescimento no setor de prestação de serviços. Florianópolis, apesar de ser a capital do estado, é de pouca expressão no setor industrial, apenas tem destaque no setor de softwares. A liberação dos mercados a partir dos anos 90 trouxe a globalização e juntamente investimentos estrangeiros e facilidade nas importações, também trouxe a concorrência de outros países, como a China e a Índia, diante deste último fator uma redução no número de empregados na indústria regional. Como resposta a esta situação surgiram novas empresas direcionadas aos desafios que a globalização impôs (CUNHA, 1992).

O que se observa é que dentro da especialização econômica microrregional catarinense caminha em paralelo um processo de diversificação e integração das estruturas econômicas. Ao mesmo tempo em que a indústria metal mecânica está fortemente concentrada no norte do Estado, ela também está espraiada por outras microrregiões como na de Blumenau, Criciúma, Joaçaba, Rio do Sul, Lages, Chapecó e Caçador. O mesmo ocorre com a indústria têxtilvestuário que está concentrada na região de Blumenau e Brusque e espalhada por toda costa litorânea do Estado (GOULARTI FILHO, 2002). Abaixo, um quadro síntese dos principais setores produtivos distribuídos nas mesorregiões catarinense:

\begin{tabular}{|c|c|}
\hline Setor & Mesorregião \\
\hline Cerâmico, Carvão, Vestuário, Descartáveis Plásticos. & Sul \\
\hline Alimentar, Móveis. & Oeste \\
\hline Têxtil, Vestuário, Naval, Cristal. & Vale do Itajaí \\
\hline $\begin{array}{l}\text { Metalúrgica, Máquinas, Equipamentos, Material } \\
\text { Elétrico, Autopeças, Plástico, Confecções, Mobiliário. }\end{array}$ & Norte \\
\hline Madeireiro & Serrana \\
\hline Tecnológico & Grande Florianópolis \\
\hline
\end{tabular}

Quadro 02 Distribuição mesorregional dos setores produtivos catarinense.

Fonte: Elaborado pelos autores com base em: FIESC - Santa Catarina em Dados, 2012.

De uma forma resumida, "uma das peculiaridades da formação econômica de Santa Catarina é a forte presença do capital de origem local. Talvez que diferencie Santa Catarina em relação a outras regiões seja justamente a palavra forte" (GOULARTI FILHO, 2002, p. 1002). Santa Catarina, sob o aspecto econômico das divisões regionais segue padrões de desenvolvimento equilibrado entre suas regiões através da distribuição setorial produtiva. Assim, o que se busca com essa caracterização dos setores produtivos é correlacionar estes dados com as áreas de predominância dos cursos ofertados pelas IES públicas gratuitas para 
verificar se estas condizem com as políticas de demandas setoriais, enfatizadas pelo governo federal.

\section{MAPEAMENTO E ANÁlISE DAS INSTITUIÇÕES DE ENSINO SUPERIORES GRATUITAS EM SANTA CATARINA}

Quando se estuda qual o papel da Universidade, fica evidente a grande importância da mesma para o desenvolvimento da sociedade, pois ela possui um importante papel à formação de pessoas qualificadas auxiliando no desenvolvimento socioeconômico da nação (COSTA, et al., 2011, p. 110). Neste sentido, se faz necessária que existam IES para o desenvolvimento regional, cabendo ao Estado, através das políticas públicas, propiciar a expansão das IES públicas gratuita.

Como o presente artigo se concentra no estudo do território catarinense, considerando que o Estado possui 295 municípios, 19 deles concentram trinta e seis IES públicas gratuitas. Desta forma, apenas $6,44 \%$ das cidades catarinense possuem IES pública gratuita. Esta tabulação inclui todos os cursos de bacharelado, tecnólogo, licenciatura e graduação. Não contabilizado os campus do IFC de Brusque e São Bento do Sul, pois ainda não estão instalados.

\begin{tabular}{|c|c|c|c|}
\hline Mesorregião & Competência & Quantidade & Total \\
\hline \multirow{3}{*}{ Sul } & Federal & 6 & \multirow{3}{*}{7} \\
\hline & Estadual & 1 & \\
\hline & Municipal & 0 & \\
\hline \multirow{3}{*}{ Oeste } & Federal & 5 & \multirow{3}{*}{6} \\
\hline & Estadual & 1 & \\
\hline & Municipal & 0 & \\
\hline \multirow{3}{*}{ Vale do Itajaí } & Federal & 2 & \multirow{3}{*}{4} \\
\hline & Estadual & 2 & \\
\hline & Municipal & 0 & \\
\hline \multirow{3}{*}{ Norte } & Federal & 4 & \multirow{3}{*}{6} \\
\hline & Estadual & 2 & \\
\hline & Municipal & 0 & \\
\hline \multirow{3}{*}{ Serrano } & Federal & 1 & \multirow{3}{*}{2} \\
\hline & Estadual & 1 & \\
\hline & Municipal & 0 & \\
\hline \multirow{3}{*}{ Grande Florianópolis } & Federal & 6 & \multirow{3}{*}{10} \\
\hline & Estadual & 4 & \\
\hline & Municipal & 1 & \\
\hline \multicolumn{2}{|c|}{ Total Geral } & \multicolumn{2}{|l|}{36} \\
\hline
\end{tabular}

Quadro 03 Distribuição Mesorregional das Instituições de Ensino Superior Públicas Gratuitas em Santa Catarina $-2013$.

Fonte: Elaborada pelos autores. 
Com base na distribuição mesorregional das instituições de ensino superior públicas gratuitas em Santa Catarina se pode concluir que a maior parte delas estão concentradas na mesorregião da Grande Florianópolis, com dez instituições de ensino, em segundo lugar está a mesorregião Sul, com sete, em terceiro, Norte e Oeste com seis cada uma, em quinto, Vale do Itajaí com quatro e em sexto, a mesorregião Serrana com duas IES públicas gratuitas.

Com relação à competência de ordem Municipal, Estadual e Federal, o maior número de IES públicas gratuitas em Santa Catarina é de competência Federal que possui $64,71 \%$ do total.

Ao analisar e tabular a distribuição mesorregional IES públicas gratuitas que oferta apenas mais de três cursos superiores, o número total cai 55,55\% com relação ao número de trinta e seis instituições, totalizando dezesseis instituições distribuídas em apenas dez cidades, significando que apenas 3,39\% das cidades catarinense possuem IES pública gratuita que oferta mais de três cursos superiores, distribuídas nas mesorregiões da seguinte forma:

\begin{tabular}{|c|c|c|c|c|}
\hline Mesorregião & Competência & Quantidade & Total & IES/Cidade \\
\hline \multirow{3}{*}{ Sul } & Federal & 1 & \multirow{3}{*}{1} & UFSC - Araranguá \\
\hline & Estadual & 0 & & \\
\hline & Municipal & 0 & & \\
\hline \multirow{3}{*}{ Oeste } & Federal & 2 & \multirow{3}{*}{3} & IFC- Concórdia / UFFS - Chapecó \\
\hline & Estadual & 1 & & UDESC - Chapecó \\
\hline & Municipal & 0 & & \\
\hline \multirow{3}{*}{ Vale do Itajaí } & Federal & 1 & \multirow{3}{*}{1} & IFC - Rio do Sul (Urbano) \\
\hline & Estadual & 0 & & \\
\hline & Municipal & 0 & & \\
\hline \multirow{3}{*}{ Norte } & Federal & 2 & \multirow{3}{*}{3} & IFC - Araguari/ UFSC - Joinville \\
\hline & Estadual & 1 & & UDESC - Joinville \\
\hline & Municipal & 0 & & \\
\hline \multirow{3}{*}{ Serrano } & Federal & 1 & \multirow{3}{*}{2} & UFSC - Curitibanos \\
\hline & Estadual & 1 & & UDESC - Lages \\
\hline & Municipal & 0 & & \\
\hline \multirow{3}{*}{ Grande Florianópolis } & Federal & 3 & \multirow{3}{*}{6} & $\begin{array}{l}\text { IFSC - Florianópolis/ IFSC - Florianópolis } \\
\text { Continente / UFSC - Florianópolis }\end{array}$ \\
\hline & Estadual & 2 & & UDESC - Florianópolis \\
\hline & Municipal & 1 & & USJ - São José \\
\hline \multicolumn{2}{|c|}{ Total Geral } & \multicolumn{2}{|l|}{16} & \\
\hline
\end{tabular}

Quadro 04 Distribuição das IES públicas gratuitas que oferta mais de três cursos superiores em Santa Catarina. Fonte: Elaborada pelos autores.

UFSC - Universidade Federal de Santa Catarina. / IFC - Instituto Federal Catarinense. / UFFS - Universidade Federal da Fronteira Sul. / UDESC - Universidade do Estado de Santa Catarina. / IFSC - Instituto Federal de Santa Catarina. / USJ - Centro Universitário Municipal de São José. 
Ao realizar o mapeamento destas IES públicas gratuitas que oferta mais de três cursos superiores, se tem a seguinte configuração:

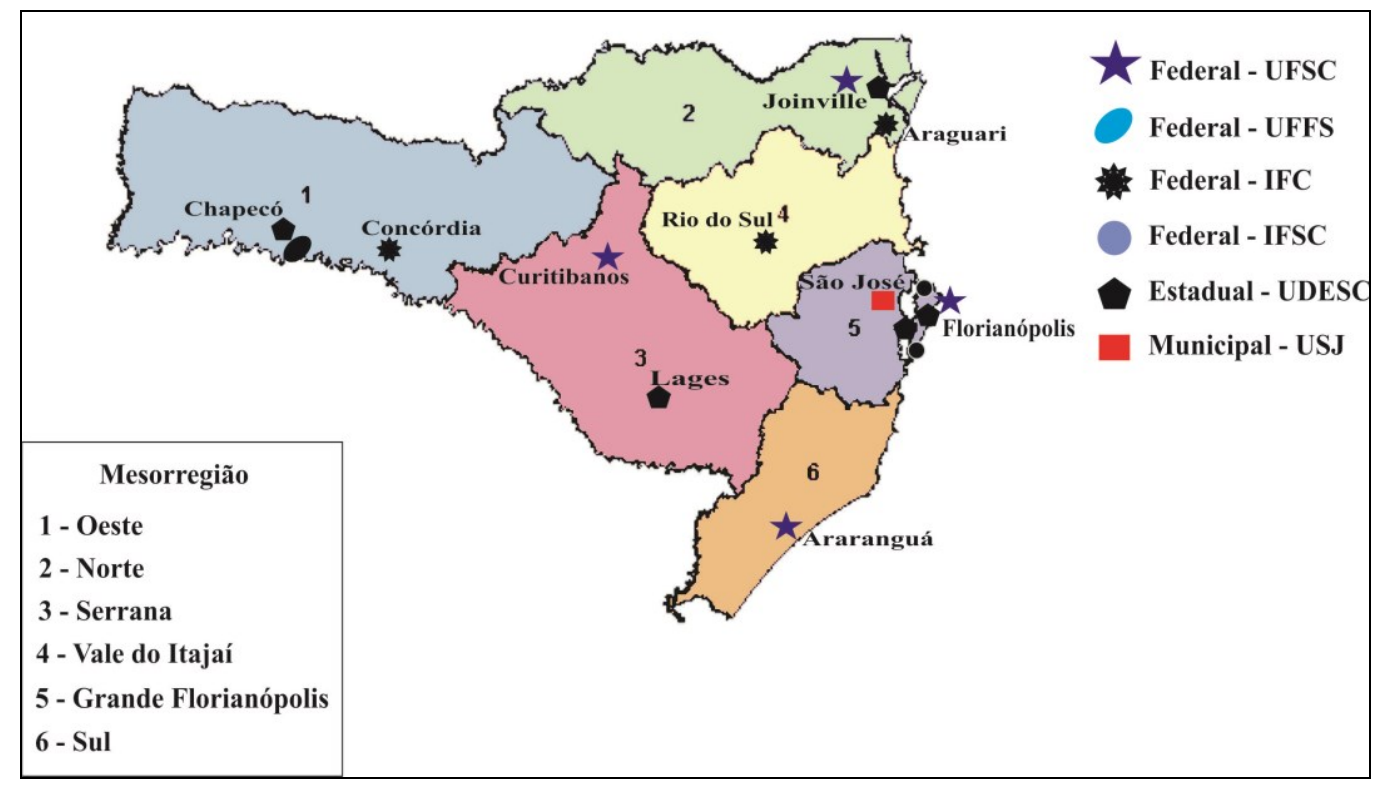

Figura 03 Mapeamento das IES Públicas Gratuitas que oferta mais de três cursos superiores em Santa Catarina. Fonte: Elaborada pelos autores.

Do total de dezesseis instituições, seis estão concentradas na mesorregião da Grande Florianópolis, ou seja, 37,50\% do total. A mesorregião Norte e Oeste concentram 18,75\% cada uma das IES públicas gratuitas que oferta mais de três cursos superiores, a mesorregiões Serrana concentra $12,50 \%$ destas IES, e as mesorregiões Sul e Vale do Itajaí detém apenas $6,25 \%$ cada uma do total de 16 IES públicas gratuitas que oferta mais de três cursos superiores. Do total de 295 municípios catarinense, 3,39\% deles (10 municípios) concentram todas as IES públicas gratuitas que oferta mais de três cursos superiores no Estado.

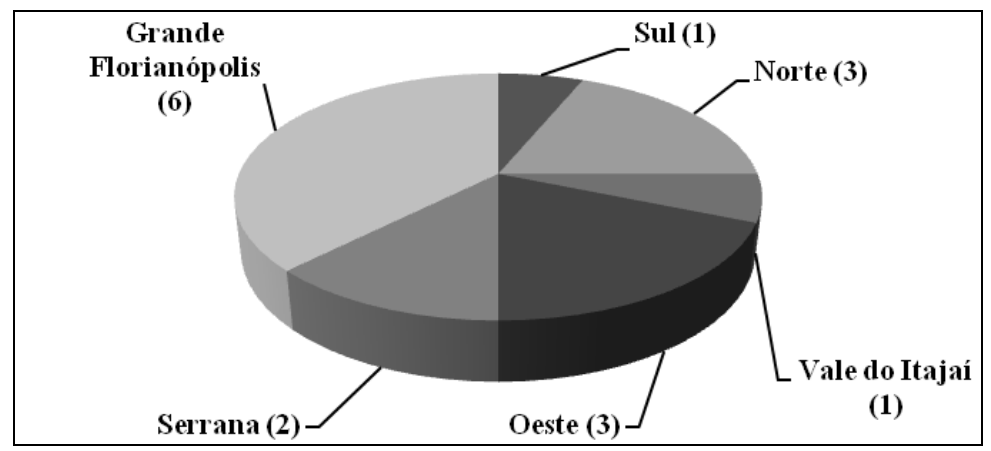

Gráfico 01 Distribuição por mesorregião das IES Públicas Gratuitas no Estado de SC que oferta mais de três cursos superiores.

Fonte: Elaborado pelos autores. 
Do total de dezesseis IES públicas gratuitas que oferta mais de três cursos superiores, 62,5\% são de competência Federal, 31,25\% Estadual e 6,25\% Municipal. De um modo geral, observando a disposição da IES públicas gratuitas que oferta mais de três cursos superiores (Figura 03), se observa que a maioria destas estão concentradas nas proximidades das regiões litorâneas. Podemos observar ainda, que na maior parte das regiões de Santa Catarina o que predomina é apenas uma IES pública gratuita que oferta mais de três cursos. Duas regiões apresentam grande nível de concentração de IES pública gratuita, a mesorregião da Grande Florianópolis e a mesorregião Norte, ambas em regiões mais próximas ao Litoral.

Existem municípios catarinense que possuem IES pública gratuita que oferta apenas um único curso superior, como é o caso de Araranguá e Jaraguá do Sul, na mesorregião Sul que possuem o IFSC, que ofertam, neste Campus, apenas Licenciatura em Física. Na mesorregião da Grande Florianópolis, em São José, o IFSC oferta apenas Licenciatura em Química.

Na mesorregião do Vale do Itajaí, em Rio do Sul, o IFC (URBANO) oferta apenas Bacharelado em Engenharia Agronômica, e a UDESC, também na mesorregião do Vale do Itajaí, em Balneário Camboriú oferta apenas Engenharia do Petróleo. O fato acaba implicando em consequências negativas, como por exemplo, fazendo com que os cidadãos não possuem a oportunidade de escolhas, ou, em outros casos, sendo necessário o seu deslocamento para outras regiões que possuam IES pública gratuita que oferta os cursos desejados. O resultado é que, muitas vezes, as políticas adotadas pelos governos não se refletem na realidade território.

Com base na tabela de classificação dos cursos por área da CAPES, foi realizada a tabulação dos cursos ofertados em cada Instituição, considerando a divisão mesorregional de $\mathrm{SC}$, e sua respectiva área de concentração. $\mathrm{Na}$ sequência, selecionamos as áreas de predominância e relacionamos com os setores produtivos econômicos de destaque, também com base da divisão mesorregional, em que estas instituições estão inseridas. Como resultado temos:

\begin{tabular}{|c|c|c|}
\hline Mesorregião & $\begin{array}{c}\text { Área de Concentração } \\
\text { Predominante }\end{array}$ & Setores Produtivos de destaque \\
\hline Sul & Engenharias & Cerâmico, Carvão, Vestuário, Descartáveis Plásticos. \\
\hline Oeste & $\begin{array}{c}\text { Ciências Agrárias } \\
\text { Ciências Humanas }\end{array}$ & Alimentar, Móveis. \\
\hline
\end{tabular}




\begin{tabular}{|c|c|c|}
\hline Vale do Itajaí & Ciências Exatas e da Terra & Têxtil, Vestuário, Naval, Cristal. \\
\hline Norte & $\begin{array}{c}\text { Engenharias } \\
\text { Ciências Exatas e da Terra }\end{array}$ & $\begin{array}{c}\text { Metalúrgica, Máquinas, Equipamentos, Material Elétrico } \\
\text { Autopeças, Plástico, Confecções, Mobiliário. }\end{array}$ \\
\hline Serrano & $\begin{array}{c}\text { Ciências Agrárias } \\
\text { Engenharias }\end{array}$ & Madeireiro \\
\hline $\begin{array}{c}\text { Grande } \\
\text { Florianópolis }\end{array}$ & $\begin{array}{c}\text { Ciências Sociais Aplicadas } \\
\text { Linguistica, Letras e Artes } \\
\text { Ciências Humanas }\end{array}$ \\
\hline
\end{tabular}

Quadro 05 Área de concentração predominante, cursos superiores - Por mesorregião.

Fonte: Elaborada pelos autores.

De um modo geral, podemos verificar que existe uma relação entre as áreas de concentração dos cursos ofertados e os setores produtivos de cada mesorregião (APL's), como por exemplo, na região norte, onde a área de concentração é a Engenharia e as Ciências Exatas e da Terra, que condiz com os setores produtivos de destaque. No entanto, conforme o estudo de Costa et al. (2011), os autores ressaltam a importância das IES conjuntamente com o Ministério da Educação focar seus esforços e suas políticas para o acesso e à permanência dos alunos nas IES, principalmente, aqueles carentes.

Desta forma, o ensino gratuito amparado e financiado pelo Estado se faz necessário, pois, ao mesmo tempo em que o aluno possui educação de qualidade, esta também é gratuita. $\mathrm{O}$ acesso ao Ensino Superior gratuito, no Estado de Santa Catarina ainda é limitado, tendo em vista que, conforme o presente estudo mostrou, existem regiões que não possuem IES gratuitas, e, em algumas delas até existe, porém, não chegam a ofertar mais de três cursos superiores, não existindo, desta forma, possibilidade de escolha de curso e acesso à IES por parte dos cidadãos. O fato implica na "não democratização" do ensino superior, sendo a solução encontrada, a entrada em IES privadas.

\section{ALGUMAS CONSIDERAÇÕES E CONTRIBUIÇÕES}

Neste artigo buscamos investigar as questões relacionadas ao acesso no Ensino Superior em Instituições públicas gratuitas no Estado de Santa Catarina, através do mapeamento e da análise de como estão distribuídas geograficamente estas instituições. Utilizamos a divisão geopolítica territorial mesorregional do IBGE e buscamos correlacionar a teoria de que cabe ao Estado a expansão das IES públicas gratuitas para dar continuidade ao 
processo de democratização do ensino superior com a realidade da distribuição das IES públicas gratuitas no Estado de Santa Catarina.

A partir dos objetivos, investigar, mapear e analisar esta distribuição chegamos aos resultados de que, do total de 16 IES públicas gratuitas que oferta mais de três cursos superiores, 37,5\% estão concentradas na mesorregião da Grande Florianópolis. As mesorregiões Norte e Oeste concentram cada uma 18,75\% das IES públicas gratuitas que oferta mais de três cursos superiores, a mesorregião Serrana concentra $12,5 \%$ destas IES, e as mesorregiões Sul e Vale do Itajaí detém apenas 6,25\% cada uma do total. Existe uma concentração maior das IES públicas gratuitas que oferta mais de 3 cursos superiores nas regiões próximas ao litoral das mesorregiões Norte e da Grande Florianópolis.

O governo federal, com as políticas do REUNI 2 teve como objetivo a interiorização das IES públicas gratuitas a partir de critérios como o Território da Cidadania e dos Arranjos Produtivos Locais (APLs), porém, no Estado de Santa Catarina até o presente momento, verifica-se que os dois Territórios da Cidadania (Meio Oeste Contestado e Planalto Norte) estão desassistidos por IES gratuita que ofertem mais de três cursos superiores.

Quanto ao quesito dos Arranjos Produtivos Locais, pode-se dizer que também faltam políticas de expansão baseados neste, como por exemplo, na mesorregião do Vale do Itajaí, (APLs de destaque: têxtil, vestuário, naval e cristal) que está praticamente sem nenhuma IES gratuita que oferte mais de três cursos superiores, possuindo apenas o IFC no município de Rio do Sul, ofertando Engenharia Agronômica, Ciências da Computação, Licenciatura em Física e Matemática, o que praticamente não condiz com o APL da região.

Assim, ao analisar o território catarinense dividido em mesorregiões, se pode claramente perceber que existem regiões que estão desassistidas de IES públicas gratuitas, como por exemplo, grande parte da mesorregião do Vale do Itajaí. Existem municípios que possuem IES que oferta apenas um único curso superior, implicando em consequências negativas à democratização do ensino superior, fazendo com que os cidadãos não possuam a oportunidade de escolhas, ou, em outros casos, sendo necessário o seu deslocamento para outras regiões que tenha IES pública gratuita que oferta os cursos desejados. Desta forma, as políticas adotadas pelos governos não se refletem na realidade território, e, não se pode ter uma democratização do Ensino Superior, e muito menos, expandir o número de vagas quando se tem IES concentradas, fazendo com que os cidadãos não tenham a oportunidade de fazer escolhas de onde e o que estudar. 
Notas

${ }^{1}$ Os Territórios da Cidadania têm como objetivos promover o desenvolvimento econômico e universalizar programas básicos de cidadania por meio de uma estratégia de desenvolvimento territorial sustentável. A participação social e a integração de ações entre Governo Federal, estados e municípios são fundamentais para a construção dessa estratégia. No estado de Santa Catarina são dois os Territórios da Cidadania: Meio Oeste Contestado e Planalto Norte. (http://www.territoriosdacidadania.gov.br)

${ }^{2}$ Todos os dados analisados estão disponíveis em: Universidade do Estado de Santa Catarina. Plano 20: planejamento estratégico 2010-2030 /Universidade do Estado de Santa Catarina Florianópolis: UDESC, 2010.

${ }^{3}$ IDH é um indicador adotado pelo Programa para o Desenvolvimento das Nações Unidas (PNUD) para mensurar o desenvolvimento humano, levando em conta a renda, saúde e educação. O índice varia de zero a um. Quanto mais próximo de 1 (um), melhor o indicador. PNUD (www.pnud.org.br). O IDH brasileiro em 2012 era de 0,730, considerado um Índice de Desenvolvimento Alto. IBGE (http://www.ibge.gov.br/paisesat/main_frameset.php).

\section{REFERÊNCIAS}

CONSTITUIÇÃO DA REPÚBLICA FEDERATIVA DO BRASIL. Obra coletiva de autoria da Editora Revista dos Tribunais. - 13. Ed. Ver., ampl. e atual. - São Paulo: Editora Revista dos Tribunais, 2008. - (RT Códigos)

CORREAA, Roberto Lobato. Espaço, um conceito-chave da geografia In: CASTRO, Ina Elias de; GOMES, Paulo Cesar da Costa; CORREA, Roberto Lobato. Geografia: conceitos e temas. Rio de Janeiro: Bertrand Brasil, 1995.

COSTA, Danilo de Melo; AMANTE, Cláudio José; COSTA, Marino Alexandre; SILVA, Cláudio Heleno Pinto da. Aspectos da reestruturação das universidades federais por meio do Reuni: um estudo no Estado de Santa Catarina. In: Revista Gestão Universitária na América Latina : Revista GUAL [1983-4535] yr: 2011 vol:4 iss:4 pg:01

COSTA GOMES, P. C. e R. L. CORREIA. Geografia, conceitos e temas. Rio de Janeiro: Bertrand Brasil, 1995.

CUNHA, Idaulo José. O salto da indústria catarinense: um exemplo para o Brasil. Florianópolis: Paralelo27, 1992.

FEDERAÇÃO DAS INDÚSTRIAS DO ESTADO DE SANTA CATARINA. Santa

Catarina em dados. Florianópolis: FIESC, v 22, p. 1-152, 2012.

GOULARTI FILHO, Alcides. Ensaios sobre a economia sul-catarinense. Criciúma: Editora da UNESC, 2005.

Formação econômica de Santa Catarina. In: Ensaios FEE, Porto Alegre, v. 23, n. 2, p. 977-1007, 2002. 
GUMBOWSKY, Argos. O Ensino Superior nas Universidades Fundacionais Municipais catarinenses: a gênese de um modelo de Ensino Superior comprometido com o desenvolvimento regional. Disponível em:

http://sbhe.org.br/novo/congressos/cbhe3/Documentos/Individ/Eixo3/460.pdf. Acesso em $15 / 07 / 2013$

HEIDEMANN, Francisco G. SALM, José Francisco. (Orgs.) Políticas Públicas e desenvolvimento: bases epistemológicas e modelos de análise. Brasília: Editora Universidade de Brasília, 2009.

INSTITUTO BRASILEIRO DE GEOGRAFIA E ESTATÍSTICA. SIDRA - Sistema IBGE de recuperação automática. Disponível em: www.ibge.gov.br

MINISTÉRIO DA EDUCAÇÃO. Disponível em: http://www.mec.gov.br . Acesso em 20 de Julho de 2013.

. Apresentação do REUNI 2. Disponível em:

http://portal.mec.gov.br/expansao/images/APRESENTACAO_EXPANSAO_EDUCACAO_S UPERIOR14.pdf. Acesso em 20 de Julho de 2013.

TERRITÓRIO DA CIDADANIA. O programa. Disponível em:

http://www.territoriosdacidadania.gov.br/dotlrn/clubs/territriosrurais/onecommunity?page_num=0\#. Acesso em 20 de Julho de 2013.

LEFEBVRE, H. The production of the space. Oxford: Blackwell, 1992 [1974].

Espacio y política. 62.ed. Barcelona: Península, 1976.

RAFFESTIN, C. Por uma geografia do poder. São Paulo: Ática, 1993 [1980].

RANGEL, Ignácio. Obras reunidas. Rio de Janeiro: Contraponto, 2005.

PROGRAMA DE APOIO A PLANOS DE REESTRUTURAÇÃO E EXPANSÃO DAS UNIVERSIDADES FEDERAIS - REUNI. Disponível em: http://reuni.mec.gov.br. Acesso em 18 de Julho de 2013.

SANTOS, M. A natureza do Espaço, Técnica e Tempo. Razão e emoção. São Paulo: HUCITEC, 1999. CAP. 6, P.114-124.

Espaço e Método. São Paulo: Nobel, 1992. CAP 2. P. 21-24.

A natureza do espaço. São Paulo: Edusp, 2002 [1996].

Espaço e Sociedade: ensaios. Petrópolis: Vozes, 1979.

SECCHI, Leonardo. Políticas públicas: conceitos, esquemas de análise, casos práticos. São Paulo: Cengage Learning, 2011. xvi, 133 p, il.

TEIXEIRA, Elenaldo Celso. O papel das políticas públicas no desenvolvimento local e na transformação da realidade. AATR - BA. 2002.Universidade do Estado de Santa Catarina. 
Plano 20: planejamento estratégico 2010-2030 /Universidade do Estado de Santa Catarina Florianópolis: UDESC, 2010.

\section{Sites Acessados:}

http://emec.mec.gov.br http://www.brasil.gov.br $\mathrm{http}: / /$ www.fecam.org.br http://www.ibge.gov.br http://www.ifc.edu.br http://www.ifsc.edu.br http://www.mec.gov.br http://www.pnud.org.br http://www.sed.sc.gov.br http://www.sidra.ibge.gov.br http://www.udesc.br http://www.ufsc.br http://www.usj.edu.br http://www.territoriosdacidadania.gov.br 